\title{
Identifikasi Keberadaan Mikroplastik Pada Caranx sexfasciatus Yang Dibudidayakan Pada Keramba Jaring Apung Di Perairan Teluk Ambon Dalam
}

\author{
Identification of The Presence of Microplastics in Caranx sexfasciatus Cultivated \\ in The Inner Ambon Bay \\ Novianty C. Tuhumury ${ }^{1 *}$, Heryan S. Pellaupessy ${ }^{1}$ \\ ${ }^{1}$ Jurusan Manajemen Sumberdaya Perairan, Fakultas Perikanan dan Ilmu Kelautan, UNPATTI, \\ Ambon, Indonesia \\ Email: "y_louhen@yahoo.com, heryanpellaupessy18@gmail.com
}

\begin{abstract}
ABSTRAK
Produksi sampah plastik yang dihasilkan terus mengalami peningkatan di perairan sehingga menjadi permasalahan global. Potongan sampah plastik berukuran kurang <5 $\mathrm{mm}$ yang disebut mikroplastik, saat ini telah mencemari lingkungan perairan baik bagi organisme maupun bagi manusia. Tujuan penelitian ini adalah mengidentifikasi keberadaan jenis dan jumlah mikroplastik pada ikan Caranx sexfasciatus yang dibudidayakan di perairan Teluk Ambon. Penelitian dilakukan pada April 2020 dengan lokasi pengambilan sampel ikan pada keramba jaring apung di perairan Teluk Ambon. Metode pengambilan sampel menggunakan metode purposive sampling yaitu penentuan sampling dengan tujuan tertentu. Analisa jenis dan jumlah mikroplastik dilakukan pada laboratorium zoology FMIPA Unpatti. Analisa data dilakukan dengan menampilkan jenis dan jumlah mikroplastik dan dibahas lebih lanjut. Hasil penelitian menunjukkan terdapat jenis film dan fiber dengan jumlah masing-masing 95 partikel dan 658 partikel. Keberadaan kedua jenis mikroplastik ini disebabkan adanya aktivitas pembuangan sampah yang berasal dari masyarakat sekitar maupun yang terbawa arus pasang surut. Berdasarkan hasil penelitian dapat disarankan untuk melakukan penelitian lanjutan tentang kandungan kimia mikroplastik pada saluran pencernaan ikan serta dampaknya melalui proses biomagnifikasi di perairan.
\end{abstract}

Kata kunci: Mikroplastik; film; fiber; Caranx sexfasciatus; Teluk Ambon

\begin{abstract}
The plastic waste production is continuing to increase in waters and has become a problem worldwide. This material, in particular for the size less than $5 \mathrm{~mm}$, called microplastic, has been polluting the environment and humans. The aim of this research, therefore, is to identify the presence of types and amount of microplastics in Caranx sexfasciatus cultivated in Ambon Bay waters. The research was conducted in April 2020 in some floating cages as a sampling site located in the Inner Ambon Bay. A purposive sampling method was applied to collect data. The types and amount of microplastics were analysed in zoology laboratory, Mathematics and Science Faculty University of Pattimura (FMIPA Unpatti). Data analysis was carried out by displaying the type and number of microplastics and discussed further. The result revealed that there were types of film and fiber with 95 particles and 685 particles, respectively. The presence of these two types of microplastics is due to the waste disposal activities that derive from the adjacent community and are carried away by tidal currents.
\end{abstract}

Keywords: Microplastic; film; fiber; Caranx sexfasciatus: Ambon Bay 


\section{PENDAHULUAN}

Permasalahan lingkungan yang mengkhawatirkan dan telah menjadi permasalahan global saat ini yaitu sampah. Sampah dihasilkan oleh manusia setiap hari dalam melakukan aktivitasnya. Aktivitas di rumah, sekolah, kantor menghasilkan sampah baik padat maupun cair. Sampah padat berupa sampah plastik merupakan jenis sampah yang paling banyak dihasilkan karena kemasan produk menggunakan plastik. Secara global, produksi plastik pada tahun 2017 mencapai 348 juta ton dan meningkat menjadi 359 juta ton di tahun 2018 (Plastics, 2019). Hal ini menunjukkan adanya peningkatan produksi sampah plastik yang dihasilkan setiap tahunnya. Sampah plastik merupakan sampah anorganik yang membutuhan waktu sangat lama untuk terurai. Proses penguraian sampah plastik terjadi akibat biodegradasi oleh mikroorganisme, fotodegradasi dengan memanfaatkan cahaya, termooksidasi dengan cahaya dan degradasi hidrolisis dengan air (Andrady, 2011). Hasil penguraian sampah plastik tersebut dikenal dengan mikroplastik dengan ukuran $<5 \mathrm{~mm}$, dan sangat berbahaya bagi kehidupan pesisir dan laut (NOAA, 2013).

Tingginya sampah plastik yang dihasilkan disebabkan oleh semakin tingginya jumlah penduduk. Pada tahun 1961, populasi manusia di dunia berjumlah sekitar 3.1 miliar meningkat menjadi 7.3 miliar di tahun 2015, dan diprediksi akan meningkat menjadi 9 miliar di tahun 2050 (Kershaw Peter J, 2016). Jumlah penduduk Kota Ambon tahun 2019 mencapai 384.132 jiwa dengan laju pertumbuhan penduduk tahun 2018-2019 sebesar 3,36\% (BPS, 2020). Dengan meningkatnya jumlah penduduk maka permintaan penggunaan plastik khususnya pada berbagai sektor contohnya untuk kebutuhan kemasan makanan dan minuman juga semakin tinggi karena kemasan plastik termasuk kategori murah, ringan dan tahan lama (Nagarajan et al., 2020).
Kawasan perairan Teluk Ambon berada di Kota Ambon sebagai ibukota propinsi yang dimanfaatkan untuk budidaya, perhubungan, pariwisata, pemukiman dan lainnya. Berbagai aktivitas yang terjadi baik di darat maupun di perairan Teluk Ambon menghasilkan sejumlah sampah padat khususnya sampah plastik. Hal ini nyata terlihat dengan banyaknya sampah terapung di perairan Teluk Ambon ketika berlangsungnya hujan. Perairan Teluk Ambon telah terkontaminasi sampah plastik khususnya tas plastik dan plastik kemasan makanan (Manullang, 2019). Sampah tersebut terbawa dari aliran sungai maupun yang dibuang langsung ke perairan oleh masyarakat sekitar. Sampah plastik akan terakumulasi di perairan dan terurai menjadi mikroplastik yang akan dikonsumsi oleh biota perairan. Meningkatnya mikroplastik dapat mengganggu ekosistem perairan (De Sales-Ribeiro et al., 2020). Telah banyak penelitian yang dilakukan tentang keberadaan mikroplastik dan dampaknya bagi pertumbuhan biota perairan (Smith et al., 2018; Critchell \& Hoogenboom, 2018). Dikatakan bahwa mikroplastik telah ditemukan pada beberapa ikan dan kerang yang dikosumsi oleh manusia (Widianarko \& Hantoro, 2018). Masyarakat Maluku sangat gemar makan ikan baik ikan budidaya maupun ikan hasil tangkapan. Salah satu ikan yang dibudidayakan di perairan Teluk Ambon pada keramba jaring apung milik Fakultas Perikanan dan Ilmu Kelautan Universitas Pattimura yaitu Caranx sexfasciatus atau dikenal dengan nama ikan bubara. Jenis ikan ini sangat digemari oleh masyarakat Maluku untuk dikonsumsi baik di rumah maupun di restaurant. Budidaya jaring apung milik Fakultas Perikanan dan Ilmu Kelautan ini ditujukan untuk kegiatan penelitian, sehingga hasil budidaya ikan diperuntukan atau dijual bagi kalangan sendiri. Untuk itulah penelitian ini dilakukan dengan tujuan untuk mengidentifikasi keberadaan mikroplastik meliputi jenis dan jumlah pada 
ikan Caranx sexfasciatus yang dibudidayakan di perairan Teluk Ambon.

\section{METODE PENELITIAN}

Penelitian ini merupakan
penelitian pendahuluan tentang keberadaan mikroplastik pada beberapa biota perairan di perairan Teluk Ambon. Penelitian dilakukan pada April 2020 di perairan Teluk Ambon (Gambar 1). Metode pengambilan sampel menggunakan metode purposive sampling yaitu penentuan sampling dengan tujuan tertentu. Sampel ikan Caranx sexfasciatus yang diambil pada keramba jaring apung berjumlah lima ekor dengan ukuran dan berat yang relatif sama Sampel ikan yang diperoleh kemudian dibawa ke Laboratorium Zoology FMIPA Unpatti untuk diteliti lebih lanjut.

Penanganan sampel ikan di laboratorium mengikuti prosedur sebagai berikut:

- Sampel ikan sebanyak lima ekor dibedah untuk diambil saluran pencernaannya dengan berat berkisar antara 2-4 gram .

- Saluran pencernaan direndam dengan menggunakan gelas beaker yang berisi aquades dicampur dengan $\mathrm{KOH}$ (kalium hidroksida) konsentrasi $10 \%$. Penggunaan $\mathrm{KOH}$ bertujuan untuk melarutkan semua bahan organik yang terkandung dalam saluran pencernaan ikan sehingga menyisakan kandungan bahan anorganik.

- Gelas beaker berisi rendaman sampel ikan ditutup dengan menggunakan kertas alumunium foil dan dibiarkan selama 14 hari pada kondisi suhu ruang.

- Sampel diamati dengan menggunakan mikroskop untuk mengidentifikasi keberadaan mikroplastik.
Data yang diperoleh kemudian dianalisa dengan menampilkan jenis mikroplastik serta jumlah dan dibahas lebih lanjut.

\section{HASIL DAN PEMBAHASAN}

Klasifikasi jenis mikroplastik terdiri dari fragmen, fiber, manik-manik, busa dan butiran/pelet (Lusher et al., 2017). Berdasarkan hasil penelitian ditemukan dua jenis mikroplastik yaitu fragmen dengan jenis film dan fiber. Fragmen dapat berupa partikel yang tidak beraturan, kristal, bulu, bubuk, granula, potongan, serpihan, film. Jenis fiber berupa filament, microfiber, helaian, benang. Jumlah mikroplastik jenis film pada kelima ikan sebesar 95 partikel, sedangkan jenis fiber sebanyak 658 partikel (Gambar 2).

Ikan Caranx sexfasciatus yang diteliti merupakan ikan yang siap dipanen atau dikonsumsi. Berat lambung pada kelima ikan tersebut berkisar antara 2-4 gram. Semakin besar ikan maka semakin besar pula jumlah makanan yang dibutuhkan. Peluang ekonomi dalam membudidayakan ikan Caranx sexfasciatus sangat menjanjikan sehingga budidaya ikan ini menjadi meningkatkan kesejahteraan masyarakat serta turut menjaga stok ikan di pasar. Untuk tetap mempertahankan produk ikan yang berkualitas maka perlu didukung oleh sistem budidaya yang tepat khususnya dalam pengelolaan kualitas air (Azhari \& Tomasoa, 2018; Zhang et al., 2020). Parameter kualitas air seperti oksigen terlarut, $\mathrm{pH}$, suhu, salinitas serta kecerahan merupakan faktor penting yang mendukung pertumbuhan ikan. Namun salah satu faktor penting lainnya yang menjadi indikator kesehatan ikan yaitu keberadaan mikroplastik. 


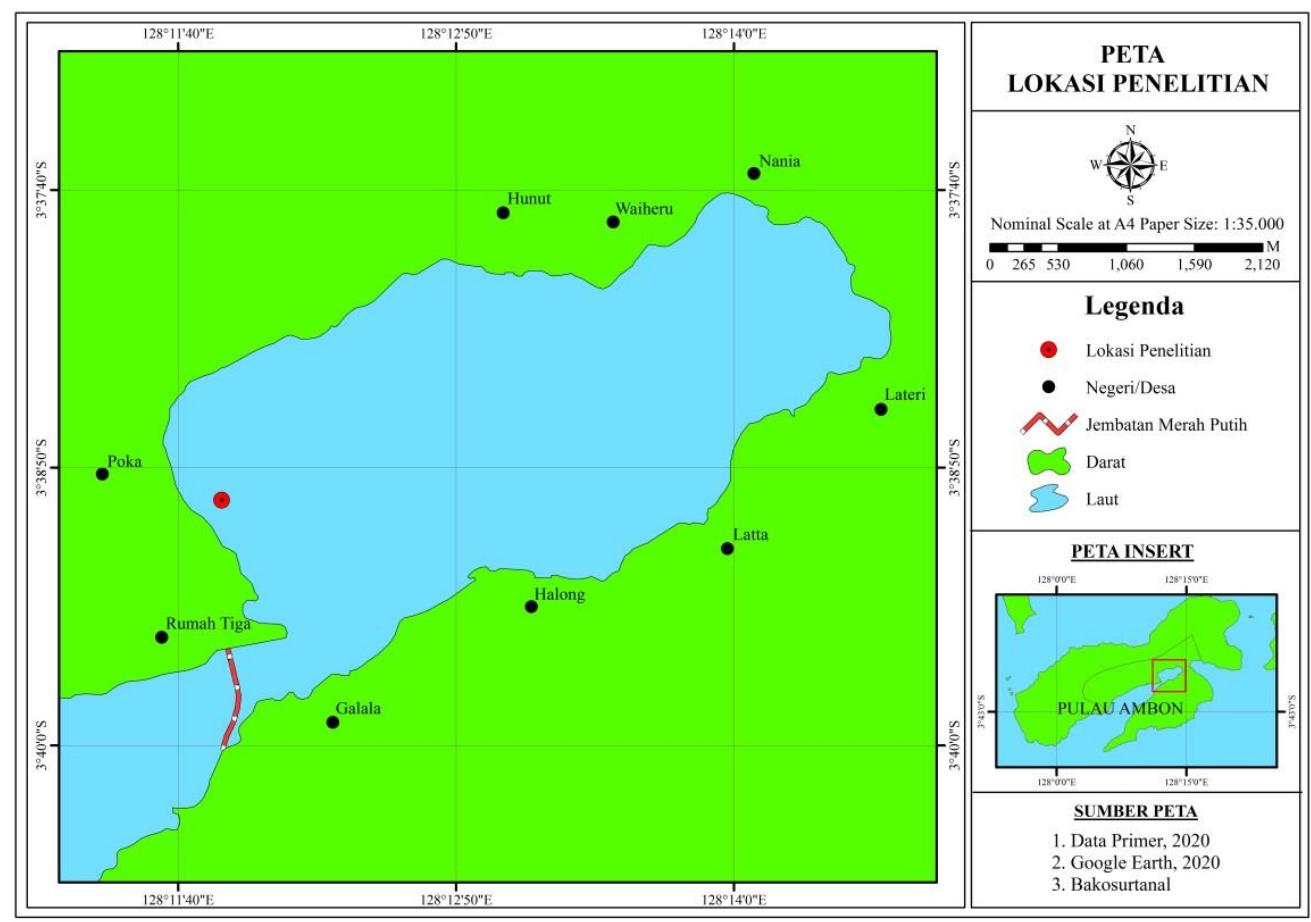

Gambar 1. Peta Lokasi Penelitian

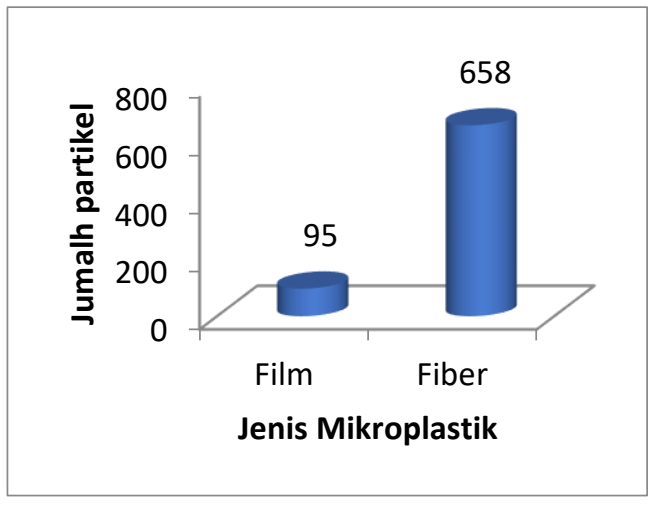

Gambar 2. Jumlah dan jenis mikroplastik pada ikan Caranx sexfasciatus

Makroplastik dan mikroplastik yang masuk ke laut bersumber dari aktivitas di darat maupun di laut. Mikroplastik diklasifikasikan dalam mikroplastik primer dan sekunder (GESAMP, 2016). Mikroplastik primer termasuk produksi pellet/bubuk dan butiran-butiran halus plastik, produk pembersih dan untuk industri abrasif. Mikroplastik sekunder berasal dari plastik ukuran besar yang terdegradasi dan mengalami fragmentasi. Sebagian besar terjadi karena degradasi pelapukan menjadi partikel mikroplastik. Jenis mikroplastik film merupakan jenis yang tidak beraturan dan lebih transparan (Gambar 3). Jenis mikroplastik film ini sangat mudah terbawa arus pasang surut karena memiliki densitas yang rendah (Dewi et al., 2015). Jenis mikroplastik ini termasuk dalam mikroplastik sekunder. Mikroplastik sekunder masuk ke lingkungan bersumber dari limbah tekstil setelah pencucian, pelapukan plastik yang digunakan untuk kegiatan pertanian yang terbawa melalui aliran permukaan tanah, pelapukan barang dari tempat pembuangan sampah, dan pelapukan sampah plastik di pesisir yang berada dalam sedimen atau dibawa lebih jauh lagi di daerah lepas pantai (Lusher et al., 2017).

Mikroplastik jenis fiber ditemukan dalam jumlah yang besar pada kelima ikan Caranx sexfasciatus (Gambar 4). Dikatakan bahwa jenis fiber ini umumnya berasal dari proses pencucian pakaian atau baju yang menghasilkan sisa serat (Crawford \& Quinn, 2017). Sumber utama mikroplastik salah satunya adalah dari sektor tekstil dan pakaian. Dalam proses pencucian pakaian akan 
menghasilkan sejumlah serat pakaian yang akan dikeluarkan dan dibuang ke perairan sehingga meningkatkan partikel mikroplastik (Kershaw Peter J, 2016).
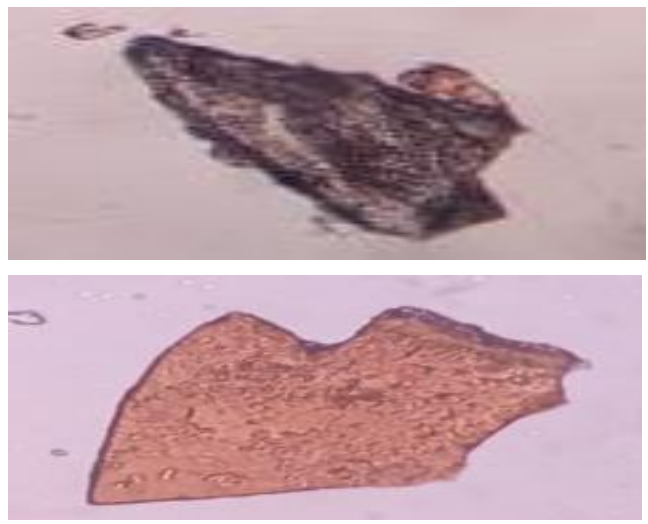

Gambar 3. Jenis mikroplastik film pada ikan Caranx sexfasciatus

Penelitian tentang bahaya mikroplastik bagi manusia masih terus dilakukan hingga saat ini. Jenis Mikroplastik yang ditemukan dalam saluran pencernaan ikan memang belum tentu membahayakan manusia, namun yang perlu diwaspadai yaitu kandungan kimia plastik yang dapat terserap dalam tubuh ikan yang dikonsumsi. Penetapan action level (AL) untuk kadar mikroplastik dalam makanan oleh pemerintah belum dilakukan (Widianarko \& Hantoro, 2018), Saat ini, mikroplastik merupakan pencemar baru yang berpotensi besar menimbulkan pencemaran pada produk pangan yang dikonsumsi oleh manusia. Berdasarkan Peraturan Badan Pengawas Obat dan Makanan Nomor 8 Tahun 2018 Tentang Batas Maksimum Cemaran Kimia Dalam Pangan Olahan menyatakan bahwa cemaran pangan adalah bahan yang tidak sengaja ada dan/atau tidak dikehendaki dalam pangan yang berasal dari lingkungan atau sebagai akibat proses di sepanjang rantai pangan, baik berupa cemaran biologis, cemaran kimia, residu obat hewan dan pestisida maupun benda lain yang dapat mengganggu, merugikan, dan membahayakan kesehatan manusia.

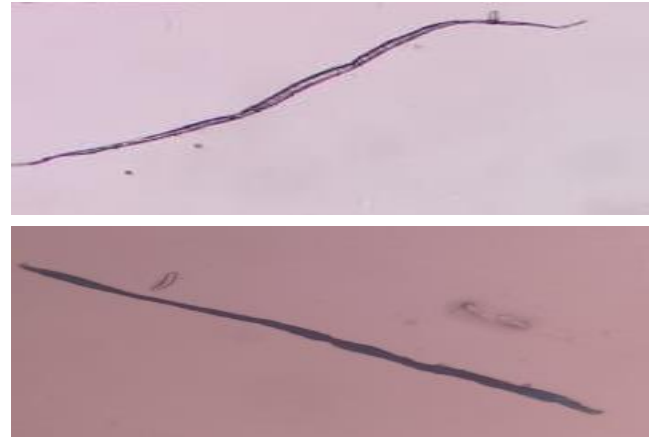

Gambar 4. Mikroplastik jenis fiber pada ikan Caranx sexfasciatus

Kawasan pesisir sekitar keramba jaring apung tempat budidaya ikan Caranx sexfasciatus ini terdapat aktivitas masyarakat serta perkapalan. Daerah pesisir dimanfaatkan masyarakat sebagai tempat pembuangan sampah. Beberapa alasan yang melatarbelakangi hal tersebut yaitu kurangnya sarana prasarana pembuangan sampah yang dapat dijangkau masyarakat, serta letak rumah penduduk yang membelakangi kawasan pesisir sehingga memudahkan masyarakat membuang sampah langsung ke kawasan pesisir. Secara visual, sampah padat berupa sampah plastik cukup banyak terdapat di daerah ini. Khususnya pada komunitas mangrove yang ada di kawasan ini, sampah plastik terjebak pada akar-akar mangrove baik yang dibuang langsung oleh masyarakat sekitar maupun yang terbawa oleh air pasang.

Kondisi arus pada perairan Poka dapat dikatakan lebih kecil dibandingkan dengan beberapa wilayah perairan Teluk Ambon Dalam, karena letaknya yang terlindung. Penelitian membuktikan bahwa berdasarkan model particle tracking pada beberapa sungai di Teluk Ambon Dalam diperoleh adanya pergerakan partikel dari sungai Waitonahitu Passo, Waiheru dan Waisala ke perairan Poka (Noya et al., 2019). Seperti diketahui sungai-sungai tersebut membawa sampah plastik yang dibuang oleh masyarakat sekitar khususnya ketika berlangsungnya hujan. Hal ini menunjukkan bahwa pergerakan sampah plastik yang terbawa dari beberapa muara sungai akan masuk ke perairan Poka. 
Pada sektor perikanan komersil telah menggunakan plastik dalam proses penangkapan, budidaya hingga pengolahan serta pemasaran produk yang dihasilkan. Alat-alat seperti jaring, tali, pelampung, tali pancing, sarung tangan, tali pengikat, kotak ikan, limbah dapur yang sudah aus atau rusak dan dibuang dengan sengaja ke perairan akan menyebabkan tingginya partikel mikroplastik (Kershaw Peter J, 2016). Bukan hanya budidaya ikan, namun juga pada budidaya tiram dan kerangkerangan lainnya yang menggunakan pelampung EPS (expanded polystyrene) yang dapat rusak maupun hilang akibat kondisi cuaca. Kegiatan lain yang berhubungan dengan perikanan tangkap yaitu perkapalan. Pada daerah sekitar keramba tersebut juga terdapat beberapa perahu dan kapal nelayan yang berlabuh di sekitar pantai Poka serta beberapa bangkai kapal. Kapal nelayan yang berlabuh melakukan kegiatan pembongkaran dan perawatan kapal di kawasan tersebut sehingga berpotensi menghasilkan mikroplastik dalam bentuk bubuk abrasif dan serpihan cat.

ikan Caranx $\begin{array}{cc}\text { Keberadaan mikroplastik pada } \\ \text { sexfasciatus }\end{array}$ yang dibudidaya di perairan Teluk Ambon ini dapat menimbulkan kekhawatiran jika dikonsumsi oleh masyarakat, walalupun hal ini perlu diteliti lebih lanjut. Kandungan bahan kimia yang terdapat pada plastik yang termakan oleh ikan atau organisme perairan dan dicerna akan menyebar pada seluruh tubuh dan dapat berpindah melalui proses rantai makanan (Chatterjee \& Sharma, 2019). Mikroplastik yang dikonsumsi oleh ikan akan membuat ikan menjadi kenyang karena dianggap sebagai makanannya. Namun ikan akan mengalami stress dan menganggu pertumbuhan hidupnya. Berdasarkan hasil penelitian di laboratorium (Rochman et al., 2013), menunjukkan bahwa ikan yang diberi makan plastik dengan kandungan $\mathrm{PAH}$ (Polycyclic aromatic hydrocarbon, PCB (polychlorinated biphenyl) dan PBDE (polybrominated biphenyl ether) menyebabkan gangguan pada hati ikan karena mengandung racun dan menimbulkan penyakit pada ikan. Partikel mikroplastik bukan hanya pada ikan namun juga pada usus burung laut sehingga menyebabkan peradangan atau inflamasi (Kershaw Peter J, 2016). Dengan kata lain partikel mikroplastik dapat berpindah berdasarkan pada tingkatan trofik (Nelms et al., 2018). Hingga saat ini penelitian tentang kontaminasi bahan kimia plastik pada tubuh manusia akibat mengkonsumsi hasil laut yang telah terkontaminasi mikroplastik masih terus dilakukan. Walaupun demikian keberadaan mikroplastik pada organisme laut telah menjadi permasalahan global yang dapat mengganggu kesehatan manusia. Selain itu, secara ekonomi keberadaan mikroplastik pada tubuh organisme laut dapat menurunkan pendapatan nelayan bahkan daerah karena kualitas ikan yang akan dikonsumsi jika diekspor menurunkan nilai jual produk. Bahaya mikroplastik yang telah nyata mencemari perairan pesisir dan laut perlu diminimalisir. Untuk menghindari perpindahan racun serta ancaman untuk masa depan hidup manusia juga, maka solusi terbaik yang dapat diberikan yaitu mengumpulkan, menggunakan kembali atau didaur ulang menjadi sesuatu yang dapat dipakai. Solusi penting lainnya adalah berhenti memproduksi plastik dan menemukan alternatif produk plastik yang dapat digunakan bagi manusia (Chatterjee \& Sharma, 2019). Selain itu, upaya pencegahan pembuangan sampah di pesisir melalui himbauan serta sanksi bagi masyarakat yang melanggar aturan perlu dilakukan. Kegiatan aksi bersih baik di tingkat warga hingga tingkat pemerintah desa dapat dijadikan agenda tetap mingguan, sejalan dengan program pemerintah kota sabtu pagi bersih lingkungan atau "sapa berlian".

\section{KESIMPULAN}

Berdasarkan hasil penelitian
diperoleh bahwa telah ditemukan
kandungan mikroplastik jenis film dan
fiber yang masing-masing berjumlah 95


partikel dan 658 partikel pada ikan Caranx sexfasciatus yang dibudidaya di perairan Teluk Ambon. Jumlah partikel mikroplastik yang ditemukan menunjukkan telah ada pencemar mikroplastik dalam tubuh ikan budidaya. Kandungan kimia dalam mikroplastik dapat membahayakan manusia melalui proses rantai makanan. Oleh karena itu, perlu dilakukan penelitian lanjutan mengenai kandungan kimia pada ikan budidaya yang dikonsumsi oleh masyarakat di perairan Teluk Ambon.

\section{DAFTAR PUSTAKA}

Andrady, A. L. (2011). Microplastics in the marine environment. Marine Pollution Bulletin, 62(2011), 15961605.

https://doi.org/10.1016/j.marpolbul. 2011.05.030

Azhari, D., \& Tomasoa, A. M. (2018). Kajian Kualitas Air dan Pertumbuhan Ikan Nila (Oreochromis niloticus) yang Dibudidayakan dengan Sistem Akuaponik. Akuatika Indonesia, 3(2), 84-90. https://doi.org/10.24198/jaki.v3i2.2 3392

BPS. (2020). Kota Ambon Dalam Angka 2020. BPS Kota Ambon. https://ambonkota.bps.go.id/publica tion/2020/04/27/0072157fa7d7bf28 8ceb130a/kota-ambon-dalamangka-2020.html

Chatterjee, S., \& Sharma, S. (2019). Microplastics in Our Oceans and Marine Health. Field Actions Science Reports. The Journal of Field Actions, 19, 54-61.

Crawford, C. B., \& Quinn, B. (2017). Microplastics, standardisation and spatial distribution. In Microplastic Pollutants.

https://doi.org/10.1016/b978-0-12809406-8.00005-0

Critchell, K., \& Hoogenboom, M. O. (2018). Effects of microplastic exposure on the body condition and behaviour of planktivorous reef fish (Acanthochromis polyacanthus).
PLoS ONE, 13(3), 1-19. https://doi.org/10.1371/journal.pone .0193308

De Sales-Ribeiro, C., Brito-Casillas, Y., Fernandez, A., \& Caballero, M. J. (2020). An end to the controversy over the microscopic detection and effects of pristine microplastics in fish organs. Scientific Reports, 10(1), $\quad 1-19$. https://doi.org/10.1038/s41598-02069062-3

Dewi, I. S., Budiarsa, A. A., \& Ritonga, I. R. (2015). Distribusi mikroplastik pada sedimen di Muara Badak, Kabupaten Kutai Kartanegara Distribution of microplastic at sediment in the Muara Badak Subdistrict , Kutai Kartanegara Regency. Depik, 4(3), 121-131. https://doi.org/10.13170/depik.4.3.2 888

GESAMP. (2016). Sources, fate and effects of microplastics in the marine environment: part 2 of a global assessment. In: Kershaw, P.J., and Rochman, C.M., eds, Rep. Stud. GESAMP No. 90 (96 pp). Reports and Studies GESAMP, 93, $220 \mathrm{p}$.

Kershaw Peter J. (2016). Marine Plastic Debris and Microplastics Global lessons and research to inspire action and guide policy change. In UNEP.

https://doi.org/10.1017/CBO978110 7415324.004

Lusher, A., Hollman, P., \& MandozaHill, J. . J. (2017). Microplastics in fisheries and aquaculture. In $F A O$ Fisheries and Aquaculture Technical Paper. https://doi.org/dmd.105.006999 [pii] \r10.1124/dmd.105.006999

Manullang, C. Y. (2019). The abundance of Plastic Marine Debris on Beaches in Ambon Bay. IOP Conference Series: Earth and Environmental Science, 253(1). https://doi.org/10.1088/17551315/253/1/012037

Nagarajan, V. M., Gopinath, K. P., Krishnan, A., Rajendran, N., \& 
Krishnan, A. (2020). A critical review on various trophic transfer routes of microplastics in the context of the Indian coastal ecosystem. Watershed Ecology and the Environment, 137421. https://doi.org/10.1016/j.scitotenv.2 020.137421

Nelms, S. E., Galloway, T. S., Godley, B. J., Jarvis, D. S., \& Lindeque, P. K. (2018). Investigating microplastic trophic transfer in marine top predators. Environmental Pollution, 238(2018), 999-1007. https://doi.org/10.1016/j.envpol.201 8.02.016

NOAA. (2013). Microplastic Marine Debris. National Ocean Service Website.

Noya, Y. A., Kalay, D. E., Purba, M., Koropitan, A. F., \& Prartono, T. (2019). Modelling baroclinic circulation and particle tracking in Inner Ambon Bay. IOP Conference Series: Earth and Environmental Science, $339(1)$. https://doi.org/10.1088/17551315/339/1/012021

Plastics, E. (2019). Plastics-The Facts 2019 An Analysis of European Plastics Production, Demand and Waste Data. https://www.plasticseurope.org/appl ication/files/1115/7236/4388/FINA L_web_version_Plastics_the_facts2 019_14102019.pdf

Rochman, C. M., Hoh, E., Kurobe, T., \& Teh, S. J. (2013). Ingested plastic transfers hazardous chemicals to fish and induces hepatic stress. Scientific Reports, 3(3263). https://doi.org/10.1038/srep03263

Smith, M., Love, D. C., Rochman, C. M., \& Neff, R. A. (2018). Microplastics in Seafood and the Implications for Human Health. Current Environmental Health Reports, 5(3), 375-386. https://doi.org/10.1007/s40572-0180206-Z

Widianarko, B., \& Hantoro, I. (2018). Mikroplastik Dalam Seafood dari Pantai Utara Jawa.
Zhang, X., Zhang, Y., Zhang, Q., Liu, P., Guo, R., Jin, S., Liu, J., Chen, L., Ma, Z., \& Ying, L. (2020). Evaluation and analysis of water quality of marine aquaculture area. International Journal of Environmental Research and Public Health, 17(4), 1-15. https://doi.org/10.3390/ijerph17041 446 